\title{
Skin changes during pregnancy. Is that an important issue for pregnant women?
}

\author{
Piotr Ciechanowicz'1, Mariusz Sikora' ${ }^{1}$, Karol Taradaj', Agnieszka Ruta², Adriana Rakowska1, \\ Bożena Kociszewska-Najman², Mirosław Wielgoś ${ }^{2}$, Lidia Rudnicka ${ }^{1}$ \\ ${ }^{1}$ Department of Dermatology, Medical University of Warsaw \\ ${ }^{2} 7^{\text {st }}$ Chair and Department of Obstetrics and Gynecology, Medical University of Warsaw
}

\begin{abstract}
Objectives: The aim of the study was to investigate the prevalence of self-reported skin complaints during pregnancy, applied treatment and the impact on well-being of pregnant women.

Material and methods: We asked 1935 women that were maximum 4 years after labor to fill in our questionnaire. The questionnaire included questions concerning the course of pregnancy, observed skin lesions, applied treatment and influence on the quality of life.

Results: Skin changes during pregnancy were reported by 1447 patients $(74.78 \%)$. The prevalence of self-reported skin complaints were as follows: stretch marks (77.4\%), acne (21.6\%) and recurrent herpes labialis (11.6\%). In 43.67\% ( $n=632)$ of women who reported dermatological problems during pregnancy the disease caused significant deterioration in their well-being. Only 168 patients (11.61\%) received dermatological treatment from their obstetricians. Dermatological consultation required 217 patients (14.99\%). For 133 of treated women $(25.68 \%)$ the recommended treatment was expensive. However, in the majority of patients $(379 ; 73.15 \%)$ who received treatment the skin changes resolved after therapy. Skin symptoms resolved significantly faster in the treated group ( $3.5 \pm 4.3$ week vs $5.8 \pm 6.2$ week; $p<0.001$ ).

Conclusions: Self-reported skin complaints seem to be a relevant problem during pregnancy. Proper skin care as well as appropriate treatment applied by obstetricians and/or dermatologists may help women to recover.
\end{abstract}

Key words: acne, herpes labialis, pregnancy dermatoses, stretch marks

\section{INTRODUCTION}

Pregnancy is a life period connected with various and intensive endocrine, metabolic, immunological and vascular changes in women's bodies. Regarding the skin, these conditions may range from physiological changes, common skin diseases not associated with pregnancy, to pathologic eruptions specially associated with pregnancy [1].

Recent classification of specific pregnancy dermatoses includes polymorphic eruption of pregnancy, atopic eruption of pregnancy, gestational pemphigoid and intrahepatic cholestasis [2]. The last two are quite rare, but may influence pregnancy outcome and pose a risk for foetal health [3]. Moreover, pregnancy may modify the course of numerous pre-existing dermatological conditions $[4,5]$.
Available studies show wide variations and conflicting data in the incidence of specific pregnancy dermatoses depending on the regions of the world $[1,4,6]$.

\section{Objectives}

The objective of our study was to determine the prevalence and type of self-reported skin changes during pregnancy as well as their influence on pregnant women.

\section{MATERIAL AND METHODS}

This questionnaire-based cross-sectional study was conducted in Warsaw nurseries among women, being no longer than 4 years after the labour. The participants were asked to fill an authorial questionnaire (see below). Women 
who were pregnant at the moment of the study, the surveys that were filled out wrong or those containing incomplete answers to the questions were excluded from the study. Data were collected consecutively between January 2015 and February 2017.

\section{Questionnaire}

Patients were asked to answer the following questions:

1. Have they suffered from any skin disorder? If yes, what was/were the disease/diseases?

2. In which trimester the symptoms appeared?

3. Did the disease cause deterioration in well-being?

4. Did the symptoms occur before pregnancy?

5. If the symptoms had occurred before pregnancy, during the pregnancy they: became less/more intense?

6. Did the symptoms occur during the previous pregnancy?

7. Did the condition influence the course of pregnancy or labor?

8. Was any treatment applied (if yes, what treatment)?

9. Did a gynecologist prescribe any medication for the disease?

10. Did you visit a dermatologist due to the disease?

11. Was the treatment financially straining: yes/no?

12. Did the symptoms subside after the treatment (if yes, when)?

13. Have the symptoms remained after the labor?

14. What time after the labor did the symptoms subside?

\section{Statistical analysis}

The data were statistically analyzed using Statistica 12.5 software (StatSoft, Poland). For comparison of quantitative variables with distributions close to normal, Student's t-test was used. In case of variables with distributions not close to normal, U Mann-Whitney test was applied. Qualitative variables were compared with the use of chi-square test. Quantitative variables were presented as median with mean standard deviation. The $p$ values $<0.05$ were considered significant.

\section{RESULTS}

A total of 1935 women were included in the study. Of these, $60.46 \%(n=1170)$ were pregnant once, $28.47 \%$ $(n=551)$ twice, whereas $11.07 \%(n=214)$ were pregnant three times or more. Age of the respondents ranged from 18 years to 40 years (mean age $28.08 \pm 3.85$ years). Anthropometric data of the respondents are presented in Table 1.

The majority of patients $(74.78 \%, n=1447)$ reported the occurrence of dermatological problems during the last pregnancy. Stretch marks $(77.4 \%$ of patients with dermatological conditions, $\mathrm{n}=1120$ ) were the most common, followed by acne $(21.6 \%, n=313)$ and herpes labialis $(11.6 \%$, $\mathrm{n}=168$ ). Figure 1 shows a distribution of all dermatological conditions reported in the questionnaire. There were no significant differences in self-reported skin problems depending on the trimester of pregnancy. Dermatological changes appeared in the first trimester in $23.61 \%(n=457)$ of women, in the second trimester in $21.55 \%(n=417)$ and in the third trimester of pregnancy in $29.6 \%(n=573)$. The difference in proportion of skin changes between primigravida and multigravida was statistically insignificant.

Additionally, $43.67 \%(n=632)$ of women who reported dermatological problems during pregnancy complained that the disease had caused deterioration in their well-being. In $47.61 \%(n=689)$ of respondents the symptoms occurred prior to the pregnancy and in $67.3 \%(n=464)$ of them the pregnancy exacerbated preexisting dermatoses. In $22.6 \%$ ( $n=327$ ) of women the disease symptoms appeared during the previous pregnancy. No differences in the duration of symptoms were observed between patients in whom a skin lesion appeared for the first time during pregnancy and those in whom a relapse of dermatosis existing prior to pregnancy occurred.

In most cases the severity of skin problems was assessed as mild. Only $1.6 \%(n=23)$ and $1.3 \%(n=19)$ of the affected women reported that the disease had influence on the course of pregnancy and labor, respectively. Reported skin problems

\begin{tabular}{|l|c|c|c|}
\hline \multicolumn{2}{|l|}{ Table 1. Anthropometric data of the respondents } \\
\hline Parameter & Mean \pm SD & Min. value & Max. value \\
\hline Height $[\mathrm{m}]$ & $1.61 \pm 0.032$ & 1.54 & 1.88 \\
\hline Weight before pregnancy $[\mathrm{kg}]$ & $62.48 \pm 8.87$ & 40 & 95 \\
\hline Weight after pregnancy $[\mathrm{kg}]$ & $74.2 \pm 9.67$ & 48 & 95 \\
\hline Current weight $[\mathrm{kg}]$ & $65.26 \pm 9.94$ & 38 & 95 \\
\hline BMl before pregnancy $\left[\mathrm{kg} / \mathrm{m}^{2}\right]$ & $22.54 \pm 3.46$ & 16.1 & 34.89 \\
\hline BMl during pregnancy $\left[\mathrm{kg} / \mathrm{m}^{2}\right]$ & $27.1 \pm 2.94$ & 17.6 & 37.8 \\
\hline Current BMI $\left[\mathrm{kg} / \mathrm{m}^{2}\right]$ & $23.5 \pm 3.3$ & 15.2 & 36.85 \\
\hline
\end{tabular}

SD — standard deviation, BMI — body mass index 


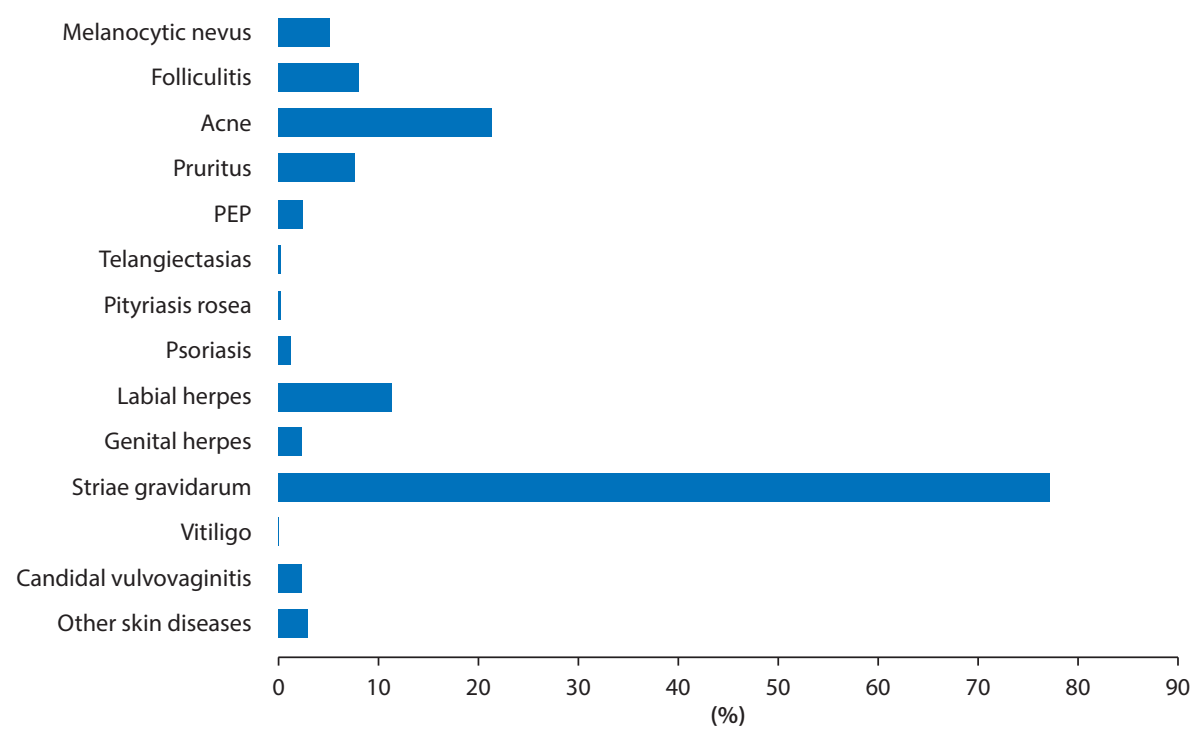

Figure 1. Distribution of all dermatological conditions reported in the questionnaire PEP - polymorphic eruption of pregnancy

resolved right after the labor in $29.2 \%(n=423)$ of patients or during the first week of puerperium $(7.9 \% ; n=115)$.

Treatment was administrated in $26.7 \%(n=518)$ of patients who reported dermatological problems. In $11.61 \%$ $(n=168)$ of cases the treatment was prescribed by obstetricians. The reported skin condition required dermatological consultation in $14.99 \%$ of women $(n=217)$. Dermatological follow-up included one visit in $48.84 \%(n=106)$ of women, two visits $-21.66 \%(n=47)$, whereas $29.5 \%(n=64)$ of women were followed-up for three visits or more. Most of the treated women $(73.17 \%, n=379)$ reported that symptoms resolved after the treatment. Most often the symptoms subsided in the first or the second week of treatment (29.34\%; $\mathrm{n}=152$ and $27.03 \% ; \mathrm{n}=140$, respectively). The symptoms resolved faster $(3.5 \pm 4.3$ week vs $5.8 \pm 6.2$ week; $p<0.001)$ in patients who received a prescribed medication for the condition. However, $25.68 \%(n=133)$ of patients found the treatment financially straining.

\section{DISCUSSION}

Skin lesions are a frequent problem of pregnant women. They are caused by hormonal, immunological and metabolic factors. However, most of them are physiological changes. In our study the frequency of self-reported skin changes was $74.78 \%$, which is in accordance with the results from other countries [1,7]. Choosing self-reported skin complaints in our analysis seems to be particularly relevant, as it may help us to understand pregnant women views and illness behavior.

A condition most frequently reported by patients was stretch marks which concerned as much as $77.4 \%$ of the pregnant women. The results were confirmed by Panicker et al. [5] who investigated a group of 600 pregnant wo- men and showed that this lesion occurs in $72.83 \%$ of them. Stretch marks are typical physiological skin lesions during pregnancy but also an important source of cosmetic concerns. They develop as a result of reduction of elastin fibers and fibrillin microfibrils in the dermis related to hormonal and physical factors. The orientation of the fibers is also changed, from the perpendicular to the dermal-epidermal junction to a parallel pattern $[8,9]$.

Hyperpigmentation is the most common physiological change in pregnant women. Increased prevalence of pigmentary changes during pregnancy is related to increased alpha-melanocyte stimulating hormone plasma concentration as well as melanocytic stimulation caused by estrogens and progesteron [10]. Kannambal et al. [1] reported pigmentary changes in $90.8 \%$, Fernandes et al. [7] observed hyperpigmentation in $87,95 \%$ of cases, Panicker et al. [6] reported hyperpigmentation in $87.6 \%$ of the studied women. In our group it is difficult to refer to the incidence of pigmentary changes because none of the interviewed women reported discoloration as a skin problem. This results from the fact that hyperpigmentation appears to be physiological change during pregnancy and patients do not regard this as uncomfortable.

According to our results, the second dermatosis most commonly reported by the examined patients was acne (21.6\% of cases). Kannambal et al., Panicer et al. and Chaudhary et al. reported acne in $13.86 \%, 10.4 \%$ and $10.33 \%$ respectively $[1,6,11]$. Despite slight differences in percentages, acne is the most common non-specific and non-infectious disorder during pregnancy. Acne exacerbation provoked by increased sebum production due to maternal androgens is often observed in the third trimester of pregnancy [12]. 
In our group of the studied female patients, recurrent herpes simplex labialis was the most frequent infection (11.6\%). The compromised immunity during pregnancy is a potential triggering factor for recurrence of the latent infection. Epidemiologic data and the potentially serious effects of transmission of genital herpes from mother to infant during birth have been widely reported, while data on oral herpes in pregnancy remain scarce [13].

A very important finding of our study is that $43.67 \%$ of women who reported dermatological problems during pregnancy complained that the disease influenced their well-being. Dissatisfaction with skin changes during pregnancy affects self-esteem and quality of life [14]. Skin changes in pregnancy might be neglected by health professionals, because most of them are physiological. The application of the treatment ordered by the doctor significantly improves skin condition.

\section{CONCLUSIONS}

Pregnant women are prone to experience a wide range of dermatological problems. The knowledge about the skin changes during pregnancy allows a health professional to properly and effectively treat the source of discomfort.

\section{Acknowledgements}

We would like to thank all women who participated in the study.

\section{REFERENCES}

1. Kannambal K, Tharini GK. A Screening Study on Dermatoses in Pregnancy. J Clin Diagn Res. 2017; 11(5): WC01-WC05, doi: 10.7860/JCDR/2017/27207.9907, indexed in Pubmed: 28658887.
2. Ambros-Rudolph CM, Müllegger RR, Vaughan-Jones $\mathrm{SA}$, et al. The specific dermatoses of pregnancy revisited and reclassified: results of a retrospective two-center study on 505 pregnant patients. J Am Acad Dermatol. 2006; 54(3):395-404, doi: 10.1016/j.jaad.2005.12.012, indexed in Pubmed: 16488288.

3. Sävervall C, Sand FL, Thomsen SF. Dermatological Diseases Associated with Pregnancy: Pemphigoid Gestationis, Polymorphic Eruption of Pregnancy, Intrahepatic Cholestasis of Pregnancy, and Atopic Eruption of Pregnancy. Dermatol Res Pract. 2015; 2015: 979635, doi: 10.1155/2015/979635, indexed in Pubmed: 26609305.

4. Kumari R, Jaisankar TJ, Thappa DM. A clinical study of skin changes in pregnancy. Indian J Dermatol Venereol Leprol. 2007; 73(2): 141, indexed in Pubmed: 17458033.

5. Makara-Studzińska M, Pietrzak A, Lewicka M, et al. Somatic and non-somatic problems connected with psoriasis in pregnancy. Ginekol Pol. 2013; 84(3): 211-213, indexed in Pubmed: 23700849.

6. Panicker VV, Riyaz N, Balachandran PK. A clinical study of cutaneous changes in pregnancy. J Epidemiol Glob Health. 2017; 7(1): 63-70, doi: 10.1016/j.jegh.2016.10.002, indexed in Pubmed: 27870929.

7. Fernandes LB, Amaral WN. Clinical study of skin changes in low and high risk pregnant women. An Bras Dermatol. 2015; 90(6): 822-826, doi: 10.1590/abd1806-4841.20153570, indexed in Pubmed: 26734862.

8. Al-Himdani S, Ud-Din S, Gilmore S, et al. Striae distensae: a comprehensive review and evidence-based evaluation of prophylaxis and treatment. Br J Dermatol. 2014; 170(3): 527-547, doi: 10.1111/bjd.12681, indexed in Pubmed: 24125059.

9. Farahnik B, Park K, Kroumpouzos G, et al. Striae gravidarum: Risk factors, prevention, and management. Int JWomens Dermatol. 2017; 3(2):77-85, doi: 10.1016/j.ijwd.2016.11.001, indexed in Pubmed: 28560300.

10. Bieber AK, Martires KJ, Stein JA, et al. Pigmentation and Pregnancy: Knowing What Is Normal. Obstet Gynecol. 2017; 129(1): 168-173, doi: 10.1097/AOG.0000000000001806, indexed in Pubmed: 27926637.

11. Chaudhary R, Mahakal N, Chauhan A, et al. Dermatological Disorders in Pregnancy: A Cross-Sectional Study. Int J Sci Study. 2015; 3(8): 118-122, doi: 10.17354/ijss/2015/522.

12. Vaughan Jones S, Ambros-Rudolph C, Nelson-Piercy C. Skin disease in pregnancy. BMJ. 2014; 348: g3489, indexed in Pubmed: 24895225.

13. Ficarra $G$, Birek $C$. Oral herpes simplex virus infection in pregnancy: what are the concerns? J Can Dent Assoc. 2009; 75(7): 523-526, indexed in Pubmed: 19744363.

14. Urasaki M. Alterações fisiológicas da pele percebidas por gestantes assistidas em serviços públicos de saúde. Acta Paulista de Enfermagem. 2010; 23(4): 519-525, doi: 10.1590/s0103-21002010000400012. 